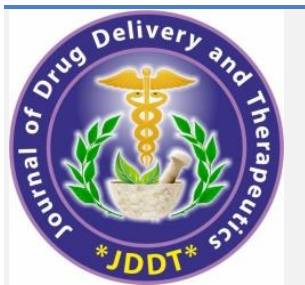

Open Access Full Text Article

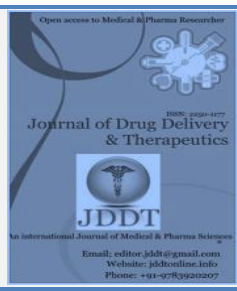

\title{
Curative impacts of Ethanoic Extract of Laportea aestuans (L) Chew in Aspirin-Induced Ulcerative compromise in Male Rats
}

\author{
Akinwande Onadeko, Olusegun Akinola* \\ Department of Biochemistry, Bowen University, Iwo, Osun State. Nigeria
}

\section{Article Info:}

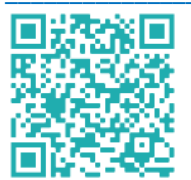

\section{Article History:}

Received 21 August 2021 Reviewed 02 October 2021

Accepted 08 October 2021

Published 15 October 2021

\section{Cite this article as:}

Akinwande 0, Olusegun A, Curative impacts of Ethanoic Extract of Laportea aestuans (L) Chew in Aspirin-Induced Ulcerative compromise in Male Rats , Journal of Drug Delivery and Therapeutics. 2021; 11(5-S):96-99

DOI: http://dx.doi.org/10.22270/jddt.v11i5-S.5027

\section{*Address for Correspondence:}

Olusegun Akinola, Department of Biochemistry, Bowen University, Iwo, Osun State. Nigeria

\section{Abstract}

Toxicity of Non-steroidal anti-inflammatory drugs (NSAIDs) are being reported with its diverse effect in the host resulting in ulcerations. Ulceration was induced orally using aspirin Twenty-four male Wistar rats were used for this study $(120-150 \mathrm{~g})$. Rats were divided into 6 groups with each group containing 4 rats. Rats were pre-treated orally with cimetidine, a reference drug. Group 1 rats orally received 1\% gum acacia solution as the control group, Group 2 rats orally administered $25 \mathrm{mg} / \mathrm{kg}$ aspirin and served as the ulcerated, untreated group, rats in groups 3 and 4 were pre-treated orally with $200 \mathrm{mg} / \mathrm{kg}$ and $400 \mathrm{mg} / \mathrm{kg}$ respectively for 3 days while rats in groups 5 and 6 were pre-treated orally with $50 \mathrm{mg} / \mathrm{kg}$ cimetidine and $50 \mathrm{mg} / \mathrm{kg}$ catechin respectively for 3 days. The result of this study shows that the ulcerated, untreated rats showed increased concentrations of The result of this study shows that the ulcerated, untreated rats showed increased concentrations of acid output, pepsin activity with a concomitant decrease in $\mathrm{pH}$ values, and mucin content compared to control group but pre-treatment with different doses, cimetidine and catechin reversed these observations. Activities of superoxide oxidase were decreased in the ulcerated, untreated group with a concomitant increase in lipid peroxidation concentration but pre-treatment with different doses, cimetidine and catechin reversed these observations. In conclusion, the ethanoic extract of $L$. aestuans can be said to be used therapeutically agaisnt aspirin-induced gastric ulcer which is due to the presence of bioactive compounds in the plant.

as an anti-ulcerogenic agent against aspirin-induced gastric ulcer which is due to the presence of phytochemicals in the plant.

Keywords: Ulcerations, bioactive compounds, oxidative stress, superoxide dismutase, aspirin

\section{INTRODUCTION}

L. aestuans ( $L$ ) Chew is mostly found in tropical rainforest habitats and greatly referred to as stinging nettle 1 . Body pains, inflamed bodily outcomes and fever are diminished by the effective powers of Aspirin-acetylsalicylic acid ${ }^{2}$. In the treatment of rheumatoid arthritis and cardiovascular thrombosis, aspirin has been widely used 14 . NSAIDs overlong usage as long term effect on the body which could lead to ulcerations, bleeding, and perforations ${ }^{2}$ threatening the lifespan of the host. Traditionally, the extracts of $L$. aestuans are used in the management of hay fever, diabetes, bronchitis and urinary problems ${ }^{12}$. It is

Epidemiological studies show that when L. aestuans is consumed, it helps to offshoot the degrading activities of free radicals in the body of the host 13 .

The importance of the phytochemical, toxicity and the antioxidant ameliorative powers of L.aestuans have been researched 11. There are two main isoforms of cyclooxygenase which emanated from arachidonic acid serving as a barrier against external forces ${ }^{10}$. COX-1 and COX-2 are generally noted in the stomach linings responsible for prostaglandins remedial activities of gastric ulcer 10 . Ulceration in the gastric mucosal is governed by the generation of gastric acid using chemicals stopping the formation of these toxic acid ${ }^{15-16}$. The present study is aimed at finding the natural antioxidants from plant materials, thus providing a natural remedy against aspirin-induced gastric ulcer to replace synthetic drugs for the management and treatment of therapeutic drug toxicity and to address the importance of medicinal plants against certain illnesses.

\section{MATERIALS AND METHODS}

All reagents and chemicals include diethyl ether, chloroform, and carbon tetra-chloride used during this work were of grade analytically. They were gotten from different sources such as BDH Chemicals, Poole, England, Sigma Chemical Company, Mo., USA.

The drugs used are aspirin (Bayer Pharmaceuticals, Germany) and cimetidine (Cimebios 200, Jiangsu Pharmaceutical Ltd. Jiangsu Province, China).

\section{Collection of plant material}

L. aestuans were collected within Bowen University, Iwo, Osun State in January 2015. For botanical identification and voucher specimen referencing was done at FRIN, Ibadan, 
Oyo State, Nigeria (Voucher specimen number: FHI 110899). Plant aunthentication was done by Dr Ayanbamiji in the Microbiology and Botany Department, Bowen University, Iwo, Osun State.

\section{Animals}

$120-150 \mathrm{~g}$ adult male wistar rats were obtained from the Veterinary Anatomy Department of University of Ibadan, kept at the animal house. They were fed ad libitum with standard rat chow throughout the period of the experiments with free access to water and were housed in polyethylene walled cages. The animals were kept on a 12 hour light: 12 hour dark regime at $28^{\circ} \mathrm{C}$. The study was by following the ethical directives (2010/63/EU) for animal handling proposed by the European parliament and was approved by the Department of Biochemistry, Animal Ethical Committee, Bowen University, Iwo, Osun State.

\section{Preparation of the leave extract of L. aestuans}

The leaves of L.aestuans were air-dried at room temperature for a period of 15 days and pulverized with electric blender (model MS-223; Blender/Miller III, Taiwan, China), and the $500 \mathrm{~g}$ of the powdered was extracted with 2. 5 liters of ethanol by maceration for 48 hours with intermittent shaking. The extract obtained was strained, filtered, evaporated to dryness on a rotatory evaporator (Model $349 / 2$ Corning/England) at $40^{\circ} \mathrm{C}$.

\section{Experimental Design and Grouping of Animals}

Twenty four Wistar rats $(120-150 \mathrm{~g})$ were used in this study. Rats were grouped into 6 groups with 4 rats in each group. Feed was withdrawn from the rat 16-18 hours before the start of the experiment but the rats were allowed access to water. Rats in Group 1 served as the control group (1\% gum acacia), Group 2 received $25 \mathrm{mg} / \mathrm{kg}$ aspirin alone (ulcerated, untreated group).

rats in Groups 3 and 4 were pre-treated for 3 days with different doses of the ethanol extract of L.aestuans, rats in Group 5 were pre-treated for 3 days with $50 \mathrm{mg} / \mathrm{kg}$ of cimetidine, rats in Group 6 were pre-treated for 3 days with $50 \mathrm{mg} / \mathrm{kg}$ of catechin. Pre-treatment was done for 3 days. On the third day, one hour after the last dose of the ethanol extract, cimetidine and catechin, $25 \mathrm{mg} / \mathrm{kg}$ of aspirin was administered orally to rats in Groups 3, 4, 5 and 6. Four hours after the administration of the ulcerogenic agent (aspirin), all the animals were sacrificed by cervical dislocation, their stomachs were excised and opened along the great curvature and the gastric contents were collected with the washings. Both the washings and gastric contents were centrifuged together at $4000 \mathrm{rpm}$ for 10 minutes, stored in test tubes and kept in a freezer at $-4{ }^{\circ} \mathrm{C}$.

\section{Statistical Analysis}

The SPSS was used and a value of $\mathrm{P}<0.05$ was statistically significant. The data were analyzed using one way analysis of variance and mean values were compared using Duncan test. Results were expressed as mean \pm standard deviation.

\section{RESULTS AND DISCUSSION}

From the below figure, rats treated with $25 \mathrm{mg} / \mathrm{kg}$ of ASP alone showed high acid output compared to the normal control group and this was statistically significant to the normal control group. Pre-treatment with different doses decreased while acid output when compared to the ulcerated, untreated group. Similarly, the group pre-treated with the reference drug, cimetedine decreased acid ouput when compared to the ulcerated, untreated group and was statistically significant to the ulcerated, untreated group. The group pre-treated with catechin also decreased the concentration of acid output when compared to the ulcerated, untreated group.

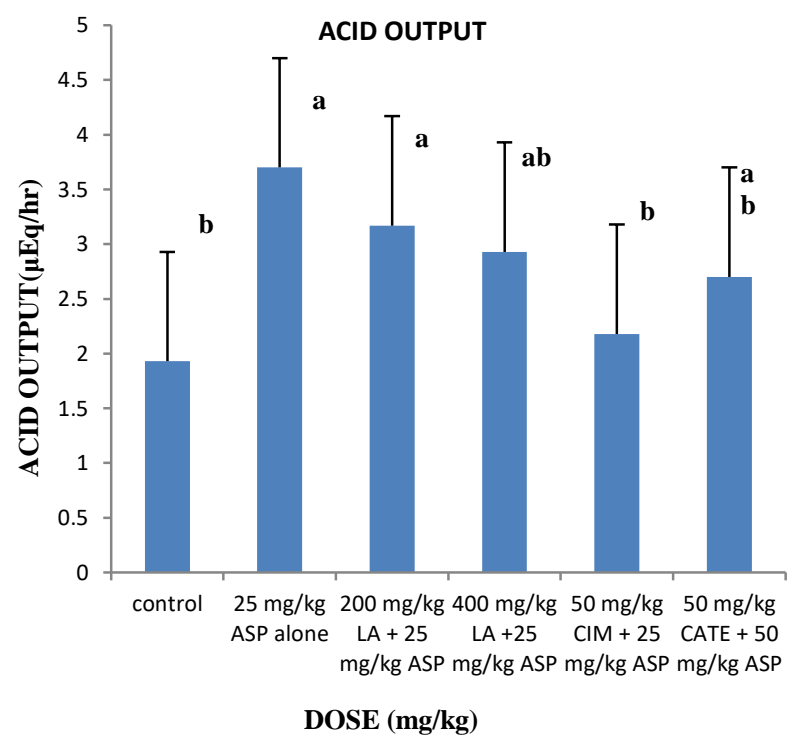

Figure 1: shows the effect of different treatment on acid output in aspirin-induced gastric ulcer in Wistar rats. Each bar represents Mean \pm SD of 4 rats. a values differ from normal control group, b values differ from ulcerated untreated group at $(\mathrm{p}<0.05)$.

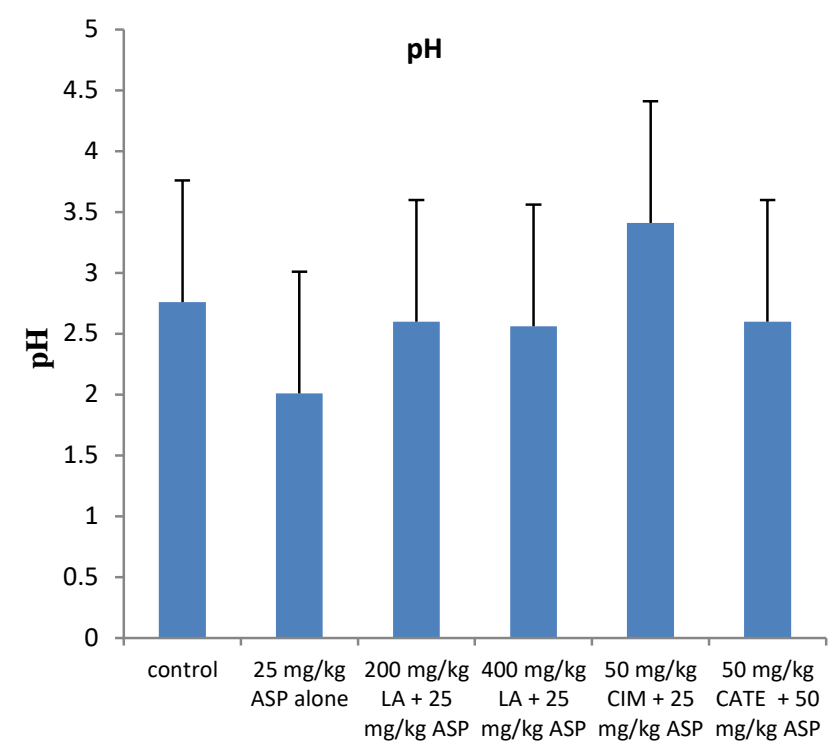

DOSE $(\mathrm{mg} / \mathrm{kg})$

Figure 2: shows the effect of different doses on $\mathrm{pH}$ in aspirininduced gastric ulcer in Wistar rats. Each bar represents Mean \pm SD of 4 rats. a value differ from normal control group.

From the figure above, rats treated with aspirin alone showed decreased $\mathrm{pH}$ value. Pre-treatment with different doses increased $\mathrm{pH}$ values when compared to the ulcerated, untreated group. Also, the group pre-treated with cimetedine increased $\mathrm{pH}$ values and was statistically significant when compared to the ulcerated, untreated group Rats pre-treated with catechin also increased $\mathrm{pH}$ concentration when compared to the ulcerated, untreated group. 


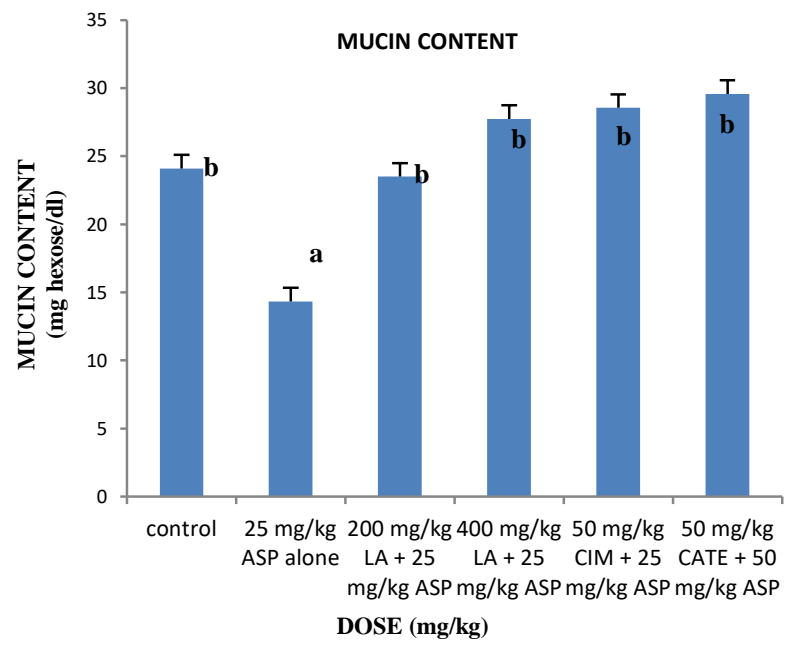

Figure 3: shows the effect of different treatment on mucin content (MC) in aspirin-induced gastric ulcer in male Wistar rats. Each bar represents Mean \pm SD of 4 rats. a value differs from normal control group. , b values differ from ulcerated untreated group at $(\mathrm{p}<0.05)$.

From the figure above, oral administration of $25 \mathrm{mg} / \mathrm{kg}$ aspirin alone showed decreased mucin content compared to the normal control group and this was statistically significant to the normal control group while groups pretreated with different doses of treatment showed an increase in mucin content and were also statistically significant to the ulcerated, untreated group. Also, the group pre-treated with cimetedine and the group pre-treated with catechin also showed an increased mucin content and were both statistically significant to the ulcerated, untreated group.

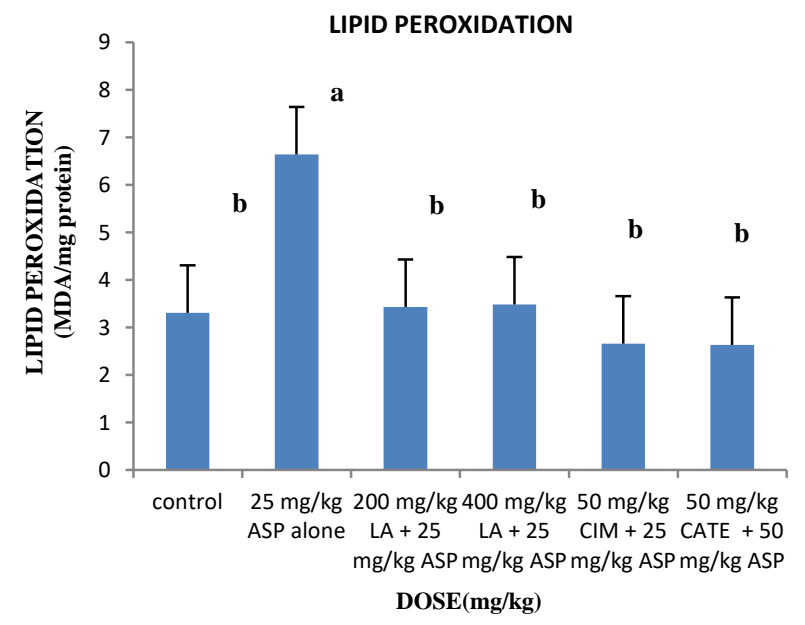

Figure 4: shows the effect of different doses on Lipid Peroxidation level in aspirin-induced gastric ulcer in male Wistar rats. Each bar represents Mean \pm SD of 4 rats. a values differ from normal control group, b values differ from ulcerated untreated group at $(\mathrm{p}<0.05)$.

From the figure above, oral administration with $25 \mathrm{mg} / \mathrm{kg}$ aspirin alone had increased lipid peroxidation compared to the normal control group which was also statistically significant from the normal control group. The groups pretreated with different doses of treatment showed decreased lipid peroxidation and was also statistically significant when compared to the ulcerated, untreated group. Pre-treatment with cimetedine and catechin also decreased lipid peroxidation and were both statistically significant when compared to the ulcerated, untreated group.

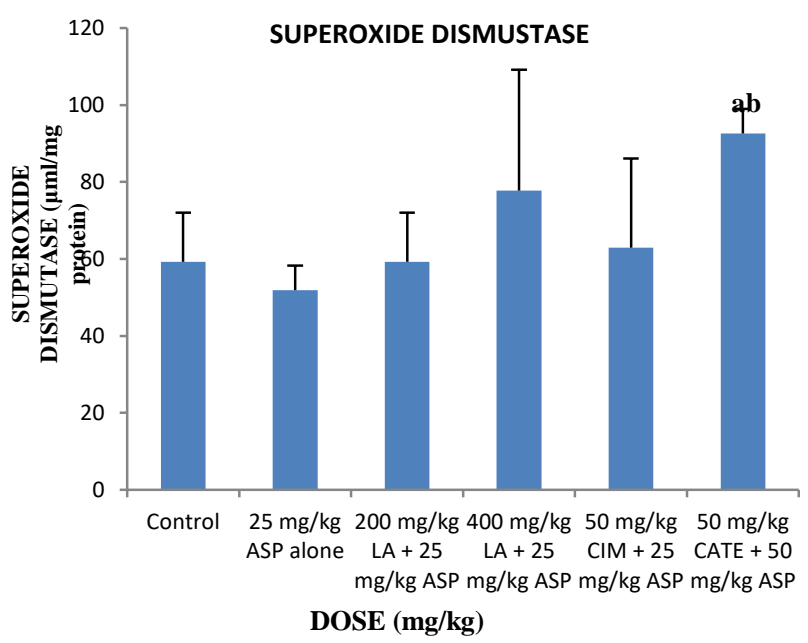

Figure 5: shows the effect of treatmen on superoxide dismustase activity in aspirin-induced gastric ulcer in male Wistar rats. Each bar represents Mean \pm SD of 4 rats. a value differ from normal control group. b values differ from ulcerated untreated group at $(\mathrm{p}<0.05)$.

From the figure above, the group treated with $25 \mathrm{mg} / \mathrm{kg}$ ASP alone showed a decrease in superoxide dismutase activity when compared to the normal control group. The groups pre-treated with different doses of treatment had increased superoxide dismustase activity compared to the ulcerated, untreated group while the group pre-treated with cimetedine showed an increase in superoxide dismutase activity and the group pre-treated with catechin increasedsuperoxide dismutase activity and was also statistically significant from the ulcerated, untreated group.

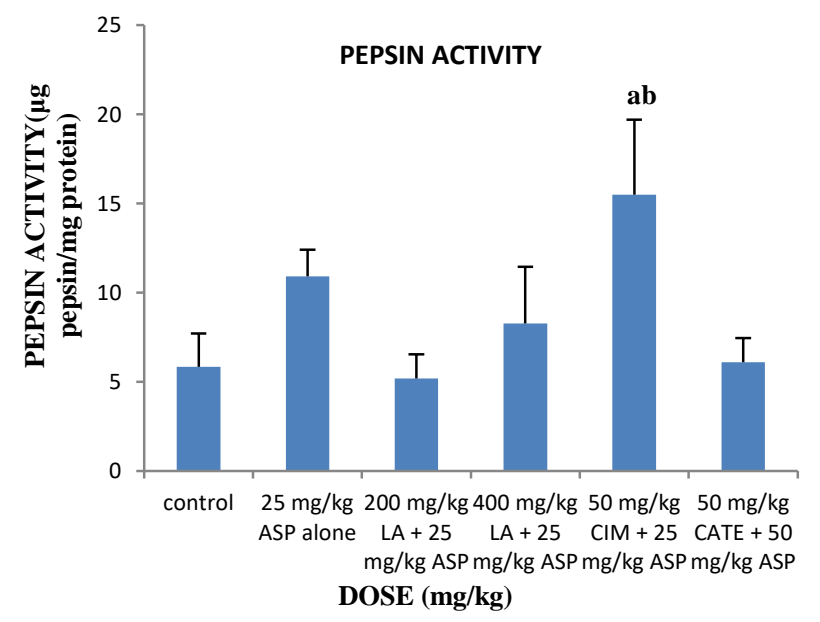

Figure 6: shows the effect of different doses on pepsin activity in aspirin-induced gastric ulcer in male Wistar rats. Each bar represents Mean \pm SD of 4 rats. a value differ from normal control group. b values differ from ulcerated untreated group at $(\mathrm{p}<0.05)$.

From the figure above, the group treated with $25 \mathrm{mg} / \mathrm{kg}$ aspirin alone showed high pepsin concentration compared to the normal control group which showed decreased pepsin concentration. Groups pre-treated with different doses decreased pepsin concentration when compared to the ulcerated, untreated group. Rats pre-treated with cimetedine however increased pepsin concentration which may be due to an increase in acid reflux and this was also statistically significant from the ulcerated, untreated group. Pre-treatment with catechin also decreased pepsin concentration. 
This study was constructed to evaluate the potential in the extract of L.astuans against aspirin-induced gastrointestinal ulcerations.

The extract was given and examined against aspirin-induced gastric ulcer. The extract was found to be very potent in fighting against gastric ulceration. This study revealed that the pre-treatment with different doses of the extract significantly increased the $\mathrm{pH}$ values. Also, the group pretreated with cimetidine and the group pre-treated with catechin all had increased $\mathrm{pH}$ values when compared to the ulcerated, untreated group. The group treated with aspirin alone had increased acid output when compared to the normal control group; this result because the aspirin hindered the stomach protective mechanism, thus allowing the sensitive stomach lining to be eroded by stomach acid and digestive juices. Groups pre-treated with different doses of the extract of $L$. aestuans and cimetidine showed decreased acid output when compared to the ulcerated, untreated group. This trend was also observed in the group pre-treated with the flavonoid, catechin. Pepsin activity decreases with an increase in $\mathrm{pH}$ level. Increased acid output increases pepsin activity. Treatment with aspirin alone showed an increase in pepsin activity when compared to the normal control group. Pre-treatment with different doses of the $L$. aestauns extract, and catechin showed a significant decrease in pepsin activity when compared to the ulcerated, untreated group. Pre-treatment with cimetidine, however, showed increased pepsin activity.

Superoxide Dismutase is an enzyme which catalyzes the dismutation of superoxide radical to form hydrogen peroxide and oxygen. It protects oxygen-metabolizing cells against harmful effects of superoxide free radicals. The assay for the determination of indirect super oxide dismutase activity is based in the inhibition of reaction between superoxide radical with adrenaline. The group treated with aspirin alone decreased the activity of super oxide dismutase when compared to the normal control group. Groups pre-treated with different doses of Laportea aestuans extract have increased superoxide dismutase activity compared to the ulcerated, untreated group. Also, the group pre-treated with cimetidine and the group pre-treated with catechin all showed increased superoxide dismutase activity.

They were found to be effective as they significantly reduced ulcerogenic parameters and increased antioxidative activities. The group treated with aspirin alone had increased gastric juice volume when compared to the normal control group. The gastric mucosa secretes large quantity of mucus which acts as a mechanical barrier resulting in the protection and strenghtening of the gastric mucosa ${ }^{8}$. Treatment with aspirin alone showed depletion of super oxide dismutase levels. Pre-treatment with different doses of L. aestuans, cimetidine and catechin showed higher reduced glutathione level which is due to their contributing antioxidant properties. The most common causes of ulceration are stress, Non- steroidal anti-inflammatory drugs and Helicobacter pylori ${ }^{3}$.A decrease in the mucosal blood flow and regeneration are important in the pathogenesis of ulcer $1-2$ with the extract of $L$. aestuans containing potent antioxidants with powerful antiulcer activities.

\section{CONCLUSION}

It is of great discovery and with the aim of this study to find out the curative importance of $L$. aestuans against gastric ulcerations which lessens the dependence of synthetic drugs theirby reducing toxicity of the host. Bioactive compounds present in the plant material have immesed advantage over ulceration when it is treated with it.

Conflict of Interest: There was no conflict of interest during the course of this work.

\section{REFERENCES}

1. Hawaii Pacific Weed Risk Assessment. Clifford P.Chimera C. Available at: http://www.hear.org/wra/ [accessed 3rd June, 2021].

2. Fornai M, Blandizzi C, Colucci R, Antonioli L, Bernardini N, Seqnani C.Role of cyclooxygenases 1 and 2 in the modulation of neuromuscular functions in the distal colon of humans and mice. Gut , 2005; 54(34):608-616. https://doi.org/10.1136/gut.2004.053322

3. Raza H, John A. Implications of altered glutathione metabolism in aspirin-induced oxidative stress and mitochondrial dysfunction in HepG2 cells. PLoS One. 2012; 7(4):2 https://doi.org/10.1371/journal.pone.0036325

4. Takeuchi K, Amagase K. Roles of Cyclooxygenase, Prostaglandin E2 and EP receptors in mucosal protection and ulcer healing in the gastrointestinal tract, Current Biophysical Pharmacology, 2018; 24(18):2002-2011. https://doi.org/10.2174/1381612824666180629111227

5. Halabi MF, Shakir RM, Bardi DA, Al-Wajeeh NS, Ablat A, Hassandarvish P, Hajrezaie, Norazit MA, Abdulla MA. Gastroprotective activity of ethyl-4-[(3, 5-di-tert-butyl-2hydroxybenzylidene) amino] benzoate against ethanol-induced gastric mucosal ulcer in rats, PLoS One .9, 2014; 2014:95908. https://doi.org/10.1371/journal.pone.0095908

6. Handa O, Naito Y, Fukui A, Omatsu T, Yoshikawa T. The impact of non-steroidalanti-inflammatory drugs on the small intestinal epithelium, Journal of Clinical Biochemistry and Nutrition. 54(2014):2-6. https://doi.org/10.3164/jcbn.13-84

7. Bandyopadhyay U, Biswas K, Chatterjee R, Bandyopadhyay D, Chattopadhyay I, Ganguly CK. Gastroprotective effect of Neem (Azadirachta indica) bark extract: Possible involvement of $\mathrm{H}(+)$ $\mathrm{K}(+)$ ATPase inhibition and scavenging of hydroxyl radical. Life Science, 2002; 71(22):2845-65. https://doi.org/10.1016/S00243205(02)02143-4

8. Cho $\mathrm{CH}$, Ogle $\mathrm{CW}$. Cholinergic- mediated gastric mast cell degradation with subsequent histamine $\mathrm{H} 1$ and $\mathrm{H} 2$ receptor activation in stress ulceration in rats. European Journal of Pharmacology, 1979; 55:(23-33). https://doi.org/10.1016/00142999(79)90144-4

9. Sarkar S, Buha D. Effect of ripe fruit pulp extract of Cucurbita pepo Linn. in aspirin induced gastric and duodenal ulcer in rats. Indian Journal of Experimental Biology, 2008; 46(2008):639-45

10. Saravanan S, Dhasarathan P, Indira V, Venkatraman R. Gastro Protective and Antioxidant Activity of Solanum nigrum linn. Against Aspirin and Cold Restraint Stress induced Ulcerated Rats. Research Journal of Immunology, 2011; 2011(4):1-11. https://doi.org/10.3923/rji.2011.1.11

11. Oloyede GK, Ayanbadejo OE. Phytochemical, toxicity, antimicrobial and antioxidant screening of extracts obtained from Laportea aestuans (Gaud). Journal of Medical Science, 2014; 14:51-59. doi: 10.3923/jms.2014.51.59. https://doi.org/10.3923/jms.2014.51.59

12. Focho DA, Ndam WT, Fonge BA (2009). Medicinal plants of Aguambu-Bamumbu in the Lebialem highlands, southwest province of Cameroon. Africa Journal of Pharmaceutics and Pharmacology, 2009; 3(1):001-013.

13. Morrison JF, Twumasi SK. Comparative studies on the in vitro antioxidant properties of methanolic and hydro-ethanolic leafy extracts from eight edible leafy vegetables of Ghana. Africa Journal of Biotechnology, 2010; 9:5177-84.

14. Wang Z, Hasegawa J, Wang X, Matsuda A, Tokuda T, Miura N, Watanabe T. Protective effects of ginger against aspirin-induced gastric ulcers in rats, Yonago Acta Medica, 2011; 54:11-19.

15. Winzler RJ. Determination of serum glycoproteins. Methods Biochemical Analytical. 1955; 2:279-311. https://doi.org/10.1002/9780470110188.ch10

16. Das SK, Roy C. The protective role of Aegle marmelos on aspirininduced gastro-duodenal ulceration in albino rat model: a possible involvement of antioxidants. Saudi Journal of Gastroenterology, 2012; 18(3):188-94. https://doi.org/10.4103/1319-3767.96452 